\title{
AutoconheCIMENTO E CURA NO SANTO DAIME: UM ESTUdO DE CASO NO CENTRO LIVRE NOSSA SENHORA DA SAÚDE
}

\author{
FRANCISCO SAVOI DE ARAÚJO
}

\begin{abstract}
RESUMO
Este trabalho possui como objetivo esclarecer alguns aspectos sobre a cura na concepção dos membros do Santo Daime, especialmente focando na igreja Centro Livre Nossa Senhora da Saúde (CLNSS), localizada no município de Lagoa Santa (MG). Trata-se de uma etnografia que possibilitou estabelecer um quadro sobre um entendimento de cura dentro do contexto religioso daimista, com a sistematização de algumas das categorias culturais êmicas que dialogam com este tema. Falar sobre cura dentro de um contexto religioso implica em compreender o corpo como inserido em um sistema cultural que the atribui significações particulares. Curas físicas, psíquicas e/ou espirituais encontram-se aqui em estreita imbricação, sendo impossível tratá-las separadamente. Se na biomedicina um doente se transforma em um paciente, no Santo Daime cada um dos "irmãos" é um agente de sua própria cura.
\end{abstract}

\section{PALAVRAS ChaVE \\ Santo Daime; Cura; Corpo.}

\section{SELF-KNOWLEDGE AND HEALING IN SANTO DAIME: A CASE-STUDY IN "CENTRO LIVRE NOSSA SENHORA DA SAÚDE"}

\begin{abstract}
This paper aims to clarify some aspects about the healing in the conception of Santo Daime members, especially focusing on the church. It is an ethnography that made it possible to establish a framework about an understanding of healing within the daimist religious context, with the systematization of some of the emic cultural categories that dialogue with this theme. Talking about healing in a religious context implies understanding the body as embedded in a cultural system that gives it particular meanings. Physical, psychic and / or spiritual healings are here in close interweaving and it is impossible to treat them separately. If in biomedicine a patient becomes a patient, in Santo Daime each of the "brothers" is an agent of his own healing.
\end{abstract}

\section{KEYWORDS}

Santo; Daime; Cure; Body.

\section{CONNAISSANCE DE SOI ET GUÉRISON À SANTO DAIME: UNE ÉTUDE DE CAS DANS "CENTRO LIVRE NOSSA SENHORA DA SAÚDE"}

\section{RÉSUMÉ}

Ce travail vise à clarifier certains aspects de la guérison dans la conception des membres de Santo Daime, en particulier en se concentrant sur l'église Centro Livre Nossa Senhora da Saúde (CLNSS), situé dans la municipalité de Lagoa Santa (MG). Il s'agit d'une ethnographie qui a permis d'établir un cadre sur une compréhension de guérison 
dans le contexte religieux daïmiste, avec la systématisation de certaines des catégories culturelles "êmicas" qui dialoguent avec ce thème. Parler de guérison dans un contexte religieux implique de comprendre le corps comme inséré dans un système culturel qui l'attribue à des significations particulières. Les guérisons physiques, psychiques et/ou spirituelles sont ici en imbrication étroite, et il est impossible de les traiter séparément. Si en biomédecine un malade se transforme en patient, à Santo Daime chacun des «frères» est un agent de sa propre guérison.

\title{
MOTS-CLÉS
}

Santo Daime; Guérir; Corps.

\section{Autoconocimiento y sanación en SANTo Daime: un estudio de Caso en "CENTRo LIVRe Nossa SENHORA DA SAÚDE"}

\section{RESUMEN}

Este artículo tiene como objetivo aclarar algunos aspectos a respecto de la curación en la concepción de los miembros del Santo Daime, especialmente direccionado en la iglesia Centro Livre Nossa Senhora da Saúde (CLNSS), ubicada en la ciudad de Lagoa Santa (MG). Se trata de una etnografía que ha posibilitado establecer un cuadro sobre un entendimiento de curación dentro del contexto religioso daimista, con la sistematización de algunas de las categorías êmicas que dialogan con ese tema. Hablar sobre curación dentro de un contexto religioso implica en comprender el cuerpo como inserido en un sistema cultural que le atribuye significaciones particulares. Curaciones físicas, psíquicas y/o espirituales son encontradas acá en estrecha imbricación, siendo imposible tratarlas en separado. Si en la biomedicina un enfermo se transforma en un paciente, en el Santo Daime cada uno de los "hermanos" es un agente de su propia curación.

\author{
PALABRAs Clave \\ Santo Daime; Curación; Cuerpo.
}




\section{INTRODUÇÃO}

Muito embora o racionalismo moderno tenha promovido no mundo ocidental a autoridade de uma nova ciência de caráter humanista enquanto fonte legítima de conhecimento sobre as verdades do mundo, frequentemente, em diferentes contextos, a dimensão da espiritualidade, ou de alguma transcendência, pode ser evocada para resolver questões ligadas à saúde/doença. As intersecções entre religiosidade e saúde geralmente vem à tona defronte a situações em que são realizados "milagres" de curas que fogem à razão da ciência ocidental moderna. Nesse sentido as noções de corpo, saúde e doença teriam características bastante singulares a cada contexto específico, dadas as particularidades cosmológicas e culturais dos diferentes sistemas religiosos difundidos por todo o mundo. Nesse sentido, este trabalho pretende examinar a partir da Antropologia as experiências de cura entre adeptos da religião do Santo Daime, especialmente na igreja denominada Centro Livre Nossa Senhora da Saúde localizada no município de Lagoa Santa, região metropolitana de Belo Horizonte - Minas Gerais.

Se o antropólogo pode ser influenciado, por meio de um exercício reflexivo, pelo desejo de transformar o estranho em familiar, automaticamente ocorrerá um efeito recursivo de estranhar-se a si próprio (DA MATTA, 1981; CARDOSO DE OLIVEIRA, 2000; SILVA, 2015). Deste modo, no transcorrer do meu contato inicial com os daimistas o estranhamento foi inevitável, tendo se manifestado em diferentes situações nas quais minhas concepções próprias foram obrigadas a se ajustar e se adaptar a visões de mundo com as quais eu jamais tivera contato.

Dentre os pontos que mais me chamaram atenção no meu convívio com os daimistas, considero as primeiras impressões fundamentais para tal exercício de reflexão. Nesse sentido, um forte aspecto que eu encontrei em campo foi que os fiéis sempre me falavam com grande entusiasmo sobre as diversas curas que recebiam como membros desta religião. A recorrência deste tipo de afirmação fez com que eu viesse a perceber o quanto o conhecimento que eu possuía até então sobre práticas de cura estava extremamente limitado à visão biomédica hegemônica, que busca desqualificar a diversidade de concepções culturais existentes acerca de saúde/doença (MONTERO, 1985).

\section{CORPO, SAÚDE E DOENÇA SOB AS LUZES DA ANTROPOLOGIA}

A Antropologia da Saúde traz uma importante contribuição para as relações entre medicina e cultura, cujos determinantes devem ser considerados a partir das particularidades de cada grupo social quanto às noções de saúde/doença que são formuladas em contextos específicos (LANGDON, 1995). Deste modo, uma experiência de adoecimento deve ser 
compreendida não exatamente "como um processo puramente biológico/corporal, mas como resultado do contexto cultural e a experiência subjetiva de aflição" (LANGDON, 1995, p. 1; grifo nosso). Considera-se aqui que todo e qualquer sistema médico só deve ser analisado se considerado enquanto produto de um "contexto cultural" mais abrangente, não cabendo uma visão fragmentária do fenômeno médico. Já o entendimento da doença enquanto "experiência subjetiva" coloca em evidência a participação ativa do doente em busca de sua cura, que passa a ser concebida como um processo que leva em conta a autonomia de cada indivíduo em transitar por entre diferentes contextos interpretativos de um meio social cujo objetivo é a cura.

Em qualquer forma de medicina, então, os fatores culturais exercem grande peso no diagnóstico e no tratamento do doente. Assim, toda experiência é mediada por um contexto que articula o biológico com o cultural, cujas crenças e valores fornecem as condições para "um processo experienciado cujo significado é elaborado através de episódios culturais e sociais, e em segundo lugar como um evento biológico" (LANGDON, 1995, p. 5). Esta perspectiva é diferenciada, segundo Langdon, porque relativiza uma biomedicina que se pretende universal em suas concepções estritamente fisicalistas das doenças.

Porém, compreendida enquanto um processo, o significado da doença vai emergir a partir da ordem e sequência estabelecida pelos próprios indivíduos em sua ação de poder criador e transformador da realidade. A primeira fase do processo é o reconhecimento dos sintomas que caracterizam aquela doença; a segunda, o diagnóstico e a opção do enfermo sobre quais os tratamentos mais adequados; por último, como atesta Langdon, está a "avaliação do tratamento".

É importante pontuar aqui a centralidade que o corpo adquire em suas dimensões significativas, fenomenológicas e interpretativas dentro de uma reflexão sobre esse tema. Estabelece-se uma relação entre corpo e cultura, não cabendo uma separação entre o que o corpo sente e o significado cultural desta sensação. Assim, a experiência subjetiva extrapola os limites internalizados do próprio indivíduo, alçando patamares da exterioridade a partir do momento em que os fenômenos sociais são compreendidos enquanto totalidade que transcende os indivíduos no que diz respeito à produção dos corpos.

Porém, tomada em suas dimensões subjetivas, a cura é considerada sob uma perspectiva que coloca no centro das atenções o indivíduo que, uma vez situado em meio a um campo semântico plural e heterogêneo vai construindo um sentido próprio para o seu processo de cura a partir de diferentes significados que podem ser atribuídos ao corpo em cada uma das culturas que convivem e se relacionam entre si nas sociedades globalizadas. De fato, toda e qualquer expressão de uma experiência subjetiva coloca em ação primeiramente uma espécie 
de síntese entre corpo e cultura que se articula em seguida às representações que esta experiência irá adquirir socialmente (ALVES; RABELO, 1998).

\section{O TRABALHO DE CAMPO: PESQUISA QUALITATIVA EM RELIGIOSIDADE E SAÚDE}

A partir das reflexões acima foram levantados alguns questionamentos que direcionam este trabalho: o que leva alguém a procurar o Santo Daime? Considerando o contexto religioso e a ideia da "cura pela fé" dentro da cosmologia daimista, como as noções de corpo e pessoa são construídas dentro desta cosmologia? Como se dá o processo de emergência e compreensão dos significados das doenças e curas dentro da doutrina daimista? Como se dão os agenciamentos dos devotos daimistas em suas diferentes buscas e demandas particulares por tratamentos de saúde? Quem são os principais agentes terapêuticos dentro do Santo Daime: o Daime, espíritos, entidades, energias, orações e no limite, o próprio indivíduo?

O que eu procuro entender é justamente como as noções de saúde/doença são concebidas na religião daimista, tendo em vista um olhar sobre o corpo, que não pode ser dissociado do cosmos em que está inserido. Um cosmos que é considerado como uma dimensão espiritual da existência; um "mundo invisível" que vai muito além daquele estritamente materialista defendido pela ciência ocidental.

Busquei, assim, abordar os questionamentos levantados acima por meio de uma experiência etnográfica própria, tomando como base: vivências pessoais realizadas em campo preliminar entre os anos de 2014 e 2016 e coleta de dados através de pesquisa de campo sistemática e observação participante entre abril e agosto de 2016, contando ainda com um conjunto de 12 entrevistas, priorizando a minha experiência na igreja Centro Livre Nossa Senhora da Saúde.

No que tange às entrevistas, o objetivo foi captar, por meio dos relatos colhidos, as experiências e concepções sobre cura, saúde e doença de cada adepto. Seguimos a orientação de "uma pesquisa de caráter êmico" (MERCANTE, 2012, p. 54), que busca os pontos de vista particulares a cada indivíduo a respeito de suas próprias experiências. Para captar como tais experiências são interpretadas, não há nada melhor do que tomar contato com as narrativas fornecidas pelas próprias pessoas que as vivenciaram, o que torna possível que as experiências sejam, pelo menos em parte, transmitidas para o pesquisador (MALUF, 2005).

Deste modo, falar de cura enquanto experiência, em sua dimensão subjetiva e vivida pelos daimistas, significa dar valor a cada uma das narrativas pessoais com suas preciosíssimas idiossincrasias, e os significados particulares atribuídos aos seus próprios processos de cura. 
Como veremos, se os sistemas de saúde são considerados a partir de códigos culturais compartilhados, nos tratamentos religiosos a doença é compreendia como um desequilíbrio de um corpo concebido para além de suas dimensões orgânicas, pois inserido em um contexto muito mais amplo que o afeta diretamente (RABELO, 2010). A aflição adquire aí significados que conduzem o doente a participar ativamente de seu processo de cura, evidenciando-se sua autonomia nas redes de relações estabelecidas ao longo de sua experiência.

\section{Centro Livre Nossa Senhora da Saúde: um CENTRO de CURA}

O Centro Livre Nossa Senhora da Saúde (CLNSS) é uma igreja do Santo Daime fundada em 19 de Março de 2005 na zona rural do município de Lagoa Santa - MG, a cerca de 4 km em estrada de terra de acesso não muito difícil a não ser pelas encruzilhadas que temos que atravessar no caminho. O "clima" da região é marcadamente bucólico, situada em uma área de Mata Atlântica com dimensão aproximada de dois hectares onde vive o José Ricardo comandante e padrinho da igreja - com sua família em uma casa à beira de um grande lago. Logo na entrada da propriedade há um belo pé de amora, e nas adjacências outras árvores que na época certa sempre estão carregadas de manga, jabuticaba, abacate, pequi, etc. Um pouco mais distante da casa do Padrinho, subindo por uma estrada que passa pelo Reinado e Jagubal', podese ter acesso à Igreja, cercada por três casas de pouso - denominadas simplesmente Casa Um; Dois; e Três - e a cozinha geral. Nas cercanias entre a cozinha geral e a casa do comandante, bem escondida em meio às matas está a casinha de Feitio, uma grande fornalha onde se faz o Daime.

\footnotetext{
${ }^{1}$ Reinado e Jagubal são lugares considerados sagrados onde se cultiva as plantas utilizadas para produzir o Daime, respectivamente a Rainha e o Jagube.
} 
FIgURA 1. No topo, VISTA Área da Fazenda São Francisco de Assis.

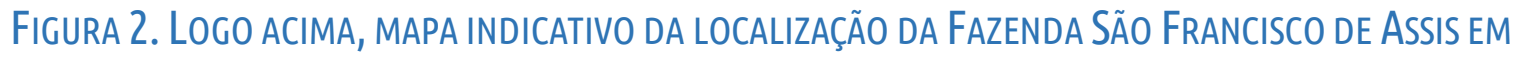
RELAÇÃO AO MUNÍCIPIO DE LAGOA SANTA.
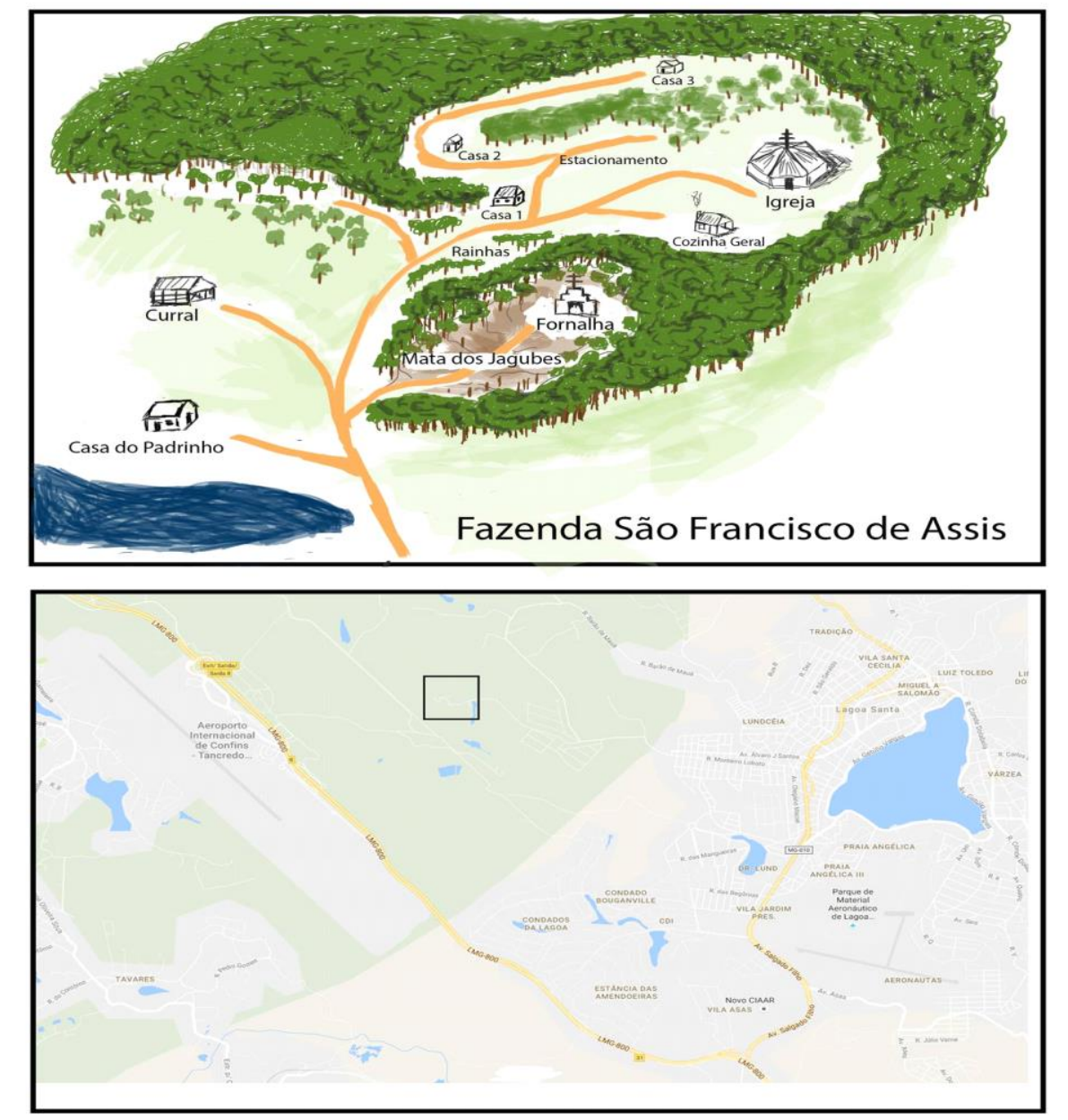

Fontes: Figura 1 - Raian Burgos/ Figura 2 - Google Maps.

Nossa Senhora da Saúde é a santa padroeira de Lagoa Santa, motivo que levou a irmandade daimista deste município a render-lhe devoção. Como relata o Padrinho Zé Ricardo, o nome Lagoa Santa deve-se aos milagres realizados na principal lagoa da região; a padroeira que a princípio era Nossa Senhora da Conceição passou a ser, então, Nossa Senhora da Saúde. Vê-se que a religiosidade católica da cidade de Lagoa Santa influenciou uma irmandade do Santo Daime a homenagear Nossa Senhora da Saúde, diluindo-se aí as fronteiras existentes entre duas religiões distintas. Acima de tudo, apesar das particularidades ritualísticas e cosmológicas de cada religião, há de se levar em conta que existe uma continuidade entre igreja Católica e Santo Daime que diz respeito à devoção cristã presente nas duas religiões, conforme argumenta o Zé Ricardo: 
Eu nasci, fui batizado na igreja Católica, na igreja de Nossa Senhora da Saúde, meu padrinho que me batizou era católico muito praticante, através dele eu sempre fui da igreja [...] ai depois eu só mudei de igreja Católica pra igreja do Santo Daime que é a mesma igreja cristã, o Jesus é o mesmo Cristo, e eu gosto também do jeito do ritual do Santo Daime, é muito envolvente, é bom, quando a pessoa gosta vai tudo mais fácil né?! Eu tenho um ponto favorável também dentro da historia da espiritualidade que é assim, como eu fui batizado nessa igreja de Nossa Senhora da Saúde a minha devoção com Nossa Senhora é grande então é uma coisa que ninguém me dobra, quando vem alguém querendo falar alguma coisa contrária eu não dou ouvido de jeito nenhum, já vou saindo por ali, porque eu tenho devoção com Nossa Senhora, eu acredito nela, eu gosto dela, eu tenho intimidade com esse ser maravilhoso (José Ricardo, entrevista realizada em abril/2016).

As pessoas que fazem parte da irmandade do CLNSS vivem em Belo Horizonte e região metropolitana, em cidades como Lagoa Santa, Santa Luzia, Contagem, Betim, Brumadinho, Nova Lima, e alguns vêm de lugares mais distantes como o município de Ouro Preto. Na época que eu comecei a frequentar a igreja haviam pessoas morando em todas as três casas de pouso: na Casa Um vivia uma mulher com suas filhas, e em cada uma das outras duas casas vivia um homem. Dessa forma, pude perceber que o CLNSS procura de alguma forma acolher pessoas em situações de necessidade para passar um tempo vivendo na fazenda, onde não falta serviço, que inclui diversos tipos de trabalhos realizados para a manutenção de uma propriedade tipicamente rural.

Na verdade, desde que cheguei a esta igreja pude notar certa rotatividade entre os moradores das casas de pouso; muitos deles moravam ali temporariamente até se estabelecerem em algo mais concreto na vida, com a aquisição de um emprego e moradia própria. De toda maneira, todos que passam pela fazenda procuram contribuir de alguma forma.

O Centro Livre Nossa Senhora da Saúde realiza, portanto, um serviço de assistência aos necessitados. Considerando tal assistência, associada à ideia de "ajuda humanitária" afirmada pelo padrinho Zé Ricardo e confirmada pela prática da caridade cristã de amparo aos doentes realizada por esta irmandade, daremos prosseguimento à discussão, enfocando as formas como os daimistas ligados a este grupo consideram seus processos de curas, considerando o contexto religioso no qual estas curas estão inseridas.

\section{O DAIME: UM VEÍCULO PARA A CURA}

A religião do Santo Daime surgiu na década de 1930 no estado do Acre sob a orientação daquele que iria a se tornar Mestre Irineu (MOREIRA; MACRAE, 2011). Dentre as influências que a cultura amazônica exerceu na formação da religião destaca-se o uso da bebida ancestral conhecida genericamente por ayahuasca que, rebatizada por Daime, transformou-se na eucaristia deste grupo religioso. Esta bebida é conhecida pelas suas propriedades psicoativas, 
com a produção de experiências místicas e visionárias muitas vezes intensas e que, em alguns casos, podem ser entendidas como uma interação com múltiplas dimensões da realidade, não visíveis nas circunstâncias ordinárias.

Apesar de existir um borbulhar sobre o uso terapêutico da ayahuasca de forma laica e científica, o foco deste trabalho passa antes de tudo pela sua utilização na religião do Santo Daime. Nesse sentido os efeitos da bebida sobre o organismo serão abordados a partir dos significados que adquirem dentro da cosmologia daimista. Como veremos adiante, tomar Daime constitui um passo fundamental no processo de cura de cada adepto desta religião; porém, em minhas incursões junto à irmandade daimista muitas pessoas me falavam que o Daime é apenas um facilitador que ajuda as pessoas a se curarem por si mesmas, ou seja, o Daime é um veículo para a cura que deve ser encontrada dentro de cada um, constituindo, ainda, necessariamente em uma busca. Como destrinchar estas explicações iniciais que a irmandade me fornecia?

É importante destacar que todas as cerimônias daimistas constituem oportunidades рага a cura. O Santo Daime é reconhecido e até mesmo autoproclamado como uma "religião da Nova Era" (MALUF, 2005; ROSE, 2005; ASSIS, 2013) que coloca em perspectiva o indivíduo, o self, enquanto agente da própria cura, independentemente da influência de agentes externos como ocorre com o protagonismo exercido por especialistas da cura como xamãs, orixás, pretosvelhos e benzedeiras, por exemplo. A ênfase aqui se dá no esforço próprio de cada adepto pela sua autotransformação e desenvolvimento pessoal, um processo de autoconhecimento que se dá mediante a viagem psicodélica proporcionada pelo uso ritual da ayahuasca.

Importa refletir, então, sobre a centralidade que a expansão da consciência possui nas curas de cada pessoa que, com o Daime, pode acessar dimensões psico-espirituais da existência não percebidas nos estados ordinários de consciência (MERCANTE, 2012). A utilização de um psicodélico como eucaristia torna o Santo Daime uma religião muito singular; a estrutura das cerimônias, que consistem basicamente em tomar Daime e cantar os hinos, propicia um setting (MACRAE, 1992) bastante favorável para que cada irmão receba os melhores benefícios da experiência que é objetivada com o uso ritual da ayahuasca na religiosidade daimista.

O transe induzido pelos efeitos da ayahuasca geralmente é acompanhado de catarses físicas e emocionais bastante intensas. No Santo Daime tais experiências são classificadas, em sua heterogeneidade, de acordo com alguns traços distintivos: são as peias; passagens; limpezas; mirações; etc. A minha decisão em tomar estas experiências como ponto de partida para tecer reflexões sobre a cura no Santo Daime se justifica na medida em que, apesar de elas nem sempre serem muito desejáveis ou agradáveis, se constituem como meios para se alcançar o propósito maior da cura que cada irmão está buscando na Doutrina, vindo a adquirir um teor 
essencialmente positivo dentro do simbolismo religioso que "relaciona a esfera de existência do homem a uma esfera mais ampla dentro da qual se concebe que ele repouse" (GEERTZ, 1989, p. 80), de tal forma a reorganizar em cada indivíduo um estado de percepção inquieta de desordem experimentada para outro de convicção mais ou menos estabelecida de ordem fundamental do mundo.

Deste modo, buscaremos refletir sobre as práticas/sentidos que o conceito de "cura" pode receber no Santo Daime.

$\star \star * * * * *$

Em se tratando de como o corpo é concebido dentro do Santo Daime, a dualidade matéria/espírito constitui uma premissa básica que fundamenta as ações de um daimista no mundo. A matéria corresponde ao corpo fisiológico, metaforizado com a figura de uma casa que faz a morada do espírito. Este por sua vez, pertence às dimensões invisíveis da realidade que, contudo, estão diretamente ligadas à dimensão visivel da matéria. Como me relatou um dos adeptos, a matéria é apenas uma "casca" andando sobre a Terra, em mútua influência com sua contraparte eterna, que é o espírito.

Nesse sentido o ser humano, enquanto um ser espiritual, não pode ser reduzido às suas condições fisiológicas que correspondem à matéria. A doutrina reencarnacionista presente no Santo Daime é centrada na ideia de que o espírito está em constante evolução ao longo de sucessivas encarnações - no sentido de se fazer carne, agir na carne (en-carne-ação) - mediante as quais pode passar por diferentes vidas ao longo de sua existência. Deste modo, somos todos espíritos encarnados; matéria e espírito constituem, assim, dimensões não excludentes entre si, na medida em que a evolução espiritual se dá na matéria, o corpo fisiológico, por meio de cada encarnação, que na verdade é uma oportunidade para o espírito galgar novos degraus em seu processo evolutivo.

Evolução espiritual pode assumir aqui uma multiplicidade de sentidos, condensados na ideia de um contínuo autoconhecimento e na busca por se corrigir os próprios defeitos de forma a cessar, gradativamente, os carmas negativos que prendem o espírito em um ciclo de nascimento e morte sobre a Terra e impedem a sua iluminação e libertação deste ciclo. O conceito de carma conforme relatado por grande parte da irmandade do CLNSS tem relações com a lei de causa e efeito (KARDEC, 2005 [1857]) que se encontra subjacente a qualquer acontecimento que ocorre com uma pessoa, como numa reação em cadeia na qual cada efeito de uma causa vai se transfigurar em uma nova causa para um novo efeito. 
Em outras palavras, considerando o livre arbítrio que conduz toda ação humana, se cada pessoa possui a consciência do que é bom e ruim em suas inter-relações e mesmo subjetivamente, cabe somente a ela decidir o caminho a seguir. Tal decisão será a causa para efeitos futuros, em uma encarnação presente ou póstuma, de acordo com a "semeadura" realizada pelas ações cometidas, seguindo a máxima cristã: "a semeadura é livre, mas a colheita é obrigatória". As "boas obras" - como diria, ainda, uma linguagem cristã - traduzidas em carmas positivos, poderiam ajudar a reduzir o ciclo de reencarnações pelas quais um espírito precisa passar рага atingir sua iluminação espiritual.

$* \star \star * * * *$

Рага um daimista todos os seres vivos possuem em si dois lados, a dimensão da sombra (negativo) e da luz (positivo), denominadas respectivamente de Eu Inferior - ou Ego - e Eu Superior. O Ego é a "voz interior" das vaidades como o ciúme, inveja, orgulho, ira, etc. enquanto o Eu Superior se expressa nas manifestações de virtudes como a humildade, caridade, paciência, etc. O relato a seguir contribui para um entendimento mais aprofundado sobre cada um desses "Eus":

Eu sou tanto o ser inferior que eu tenho que disciplinar, tenho que doutrinar e ensinar com carinho, amor, ternura e paciência, mas também este ser superior que eu quero ser e que eu já sou. Então sempre devemos estar nos aprimorando e estar atentos em especial para romper tantos hábitos mentais e tantas formas de pensar tolas que às vezes nos atrapalham, eu tenho que superar os vícios afetivos, relacionais comigo e com os outros. O principal ensinamento eu acredito que Deus está dentro de nós, e é incrível o potencial de transformação e de mudança que eu posso fazer quando eu tomo contato desse fato de que Deus está dentro de mim. A essência divina já está dentro de nós e já encontramos, mas temos que nos lembrar de que somos seres humanos, e como seres humanos temos nossa debilidades, nossas imperfeições, e reconhecer a essência divina nos dá a possibilidade de trabalhar essas imperfeições, sendo que o Eu Superior seria Deus em mim, mas muita gente não compreende, porque é algo muito particular, um trabalho muito interior, muito privado. A maioria das pessoas estão presas ao mundo material, em busca de sucesso, de grana e de status, uma vida materialista, egocêntrica e narcisista. Aí eu te digo: 'você veio aqui pra ter grana, pra ter sucesso, pra ter casa?' Na historia divina tomara que tenha saúde, prosperidade, não tô dizendo pra ter uma vida ascética, mas às vezes é importante também. O Santo Daime me ajuda a tomar consciência disso e de outros assuntos ( $R$, entrevista realizada em maio/2016).

O relato acima evidencia bem as peculiaridades de cada Eu. O Eu Inferior corresponde às vaidades e imperfeições humanas, as provações da matéria que devem ser enfrentadas, superadas e, sobretudo, doutrinadas pelo próprio indivíduo, caso o objetivo seja a sua evolução espiritual rumo à iluminação. Deste modo, a iluminação espiritual torna-se cada vez mais próxima na medida em que a pessoa vai se educando internamente/espiritualmente de modo a reconhecer e deixar de "alimentar" os seus vícios e automatismos de comportamento 
condicionados pelo Ego - compreendido como uma ilusão - que a levam consequentemente à autodestruição.

Estes princípios contribuem, assim, para a evolução espiritual de cada um. Se o Eu Inferior está ligado às ilusões da matéria, a um estilo de vida materialista e egocêntrico, o Eu Superior, em contrapartida, é entendido como o Ser Verdadeiro - a não-ilusão do Ego compreendido como a essência divina existente dentro de cada pessoa. Esse é o caminho da iluminação, na busca em se aproximar cada vez mais da verdade divina, conforme aparece no seguinte relato:

Pra mim eu tenho um conceito de espiritualismo diferente, pra mim é uma coisa mais cósmica, mais quântica, mas eu sempre tive essa coisa de não colocar um Deus limitado num homenzinho de barba, velho, ranzinza, que te pune, que te castiga, que você nunca entende o que o cara quer, tem raiva, entende? Tudo é simbólico, e a gente entende essas coisas de outra forma né, você é uma unidade de um todo complexo, uma partícula do divino (M., entrevista realizada em abril/2016)

O Deus não "limitado num homenzinho de barba", entendido de uma maneira "mais cósmica, mais quântica", corresponde à essência divina que constitui o Eu Superior. Na medida em que cada um dos seres viventes no cosmos pode ser compreendido como "uma unidade de um todo complexo", ou seja, como "partícula do divino", os limites do individualismo se perdem em benefício de uma maior harmonia do "todo", de tal forma que as vaidades do "mundo de ilusão" - o mundo egocêntrico e individualista do Ego - possam ser doutrinadas a serviço deste "Deus interior" que se manifesta em tudo que existe, onipotente, onisciente e onipresente, a Unidade cósmica.

Nossa essência primeira, nossa identidade primeira é a identidade espiritual, e às vezes a pessoa esquece disso porque ninguém ensina. Então aprofundando um pouco, quem eu sou? Eu agregaria: eu sou agora! A pergunta seria: eu sou esse que eu acreditei que era? Se muitas pessoas acreditam que o Ego é o seu Ser [...]Então na sociedade humana pode ser que a maioria das pessoas estão adormecidas nesse mundo de ilusão. No meu caso eu senti no último trabalho dentro de mim um vazio, mas não um vazio de estar vazio, mas um vazio de silêncio, de tirar de dentro de mim aquele que eu acreditava que eu era e ficar dentro do silêncio para que brote e floresça esse Ser que eu sou de verdade, sim, o Eu Superior. [...] Este é o caminho espiritual de acordar cada vez mais nosso verdadeiro ser que não é esse que acreditávamos que era, é superior! A memória divina, a inteligência natural, a inteligência divina ( $R$., entrevista realizada em maio/2016).

Considerando os dizeres de R., entende-se que a essência divina existente dentro de cada pessoa está, em muitos casos, adormecida em meio às ilusões da matéria, do Ego, o "mundo de ilusão". O Eu Superior é concebido como a matriz do Ser e de toda a existência, a identidade espiritual de cada pessoa; se cada encarnação na Terra transitória e passageira, a ideia de uma "identidade espiritual" assume aí um entendimento de "identidade" um pouco mais amplo do que aquele estritamente materialista. 
O Daime vai abrir um canal seu de você mesmo com o divino, um canal com a expressão real com aquela matriz pura né. Você como ego, como pessoa, como indivíduo, com o nome que você tem, o hábito que você tem, o social que você é, da cultura que você tem, entende? você não quer desmantelar isso, você quer morrer e levar isso com você de todo jeito, porque pra gente parece que a aniquilação de um ser seria acabar com a sua identidade, esse é um conceito basicamente materialista, isso é o materialismo, porque você acredita que o poder de tudo na sua vida tá dependendo de tudo isso que é conceito materialista, pra você ter um conceito que não seja do âmbito materialista, da nossa encarnação aqui do planeta Terra, gravidade, espaço, tempo, pra você ter uma condição de sair disso é o que a gente chama de espiritual. Pra mim é preciso que cada um seja responsável pela sua transformação, ninguém faz isso sozinho né, nada se faz sozinho, mas cada um de nós precisa desejar isso de coração e estar pronto para consequências, a consequência de autotransformar, que autotransformar e cura é a mesma coisa, são sinônimos entende? Se você consegue se enxergar como você reage? (M., entrevista realizada em abril/2016).

O despertar desta essência divina pode ser, então, assimilado com a responsabilidade individual pela própria transformação, que assume aí o entendimento da cura propriamente dita. A cura é concebida aí, portanto, como uma autotransformação gerada pelo despertar da consciência para a presença e manifestação da essência divina, o Eu Superior de cada irmão, em todas as dimensões de sua vida, se transformando cada vez mais em um ser plenamente sintonizado e conectado com Deus, que habita a tudo e a todos.

Contudo, tal "despertar" só se faz eficaz se for ato quando cada irmão pode ir gradativamente, em sua prática cotidiana, ir doutrinando as manifestações do seu ego, com muita disciplina de pensamentos e atitudes. Os (des) caminhos condicionados pelo seu Eu Inferior vão dando lugar, assim, ao seu Eu Superior, de início adormecido, que começa a despertar dentro dele. Esta á a cura do Daime, que passa pelo merecimento de cada irmão em se esforçar para alcançar a própria transformação interna no caminho de sua iluminação espiritual.

O despertar da consciência para a presença dos diferentes "Eus" ocorre durante as cerimônias, na forma de revelações fundamentais sobre o sentir, pensar, agir e estar no mundo por parte de cada irmão. Tais revelações, sendo todo aquele conteúdo interno às consciências de cada um, constituem a miração, termo daimista utilizado para designar a viagem interior que acontece em meio à expansão da consciência induzida pelo uso ritual do Daime. Esta viagem permite que seja feita uma autoanálise sobre a própria vida, no que se considera um processo de autoconhecimento quando cada um se depara frente a frente consigo mesmo, o que constitui o clímax ritual.

Uma vez imerso na miração há o contato direto com seus defeitos (Eu Inferior) e qualidades (Eu Superior). Cada um desses "Eus" são metaforizados nas diferentes sensações 
místicas extrassensoriais que podem ocorrer na viagem de cada irmão. Se, por um lado, o Eu Superior pode estar associado com o silêncio e o vazio, o contato com o Eu Inferior em meio às mirações pode ocasionar certas experiências desagradáveis, que podem ser designadas por peias e passagens. Estes são os momentos vivenciados durante a miração em que certa carga de sofrimento físico e emocional é experienciada, encarados como um grande desafio e dificuldade enfrentados durante os rituais.

Os vômitos, diarreias, choros e sudoreses que podem ocorrer nessas ocasiões, tidos por pessoas mais céticas como meros "efeitos colaterais" do Daime sobre o organismo, são compreendidos enquanto limpezas de toda a carga de energia negativa que um irmão acumula em sua matéria devido aos maus hábitos que the agridem. Neste caso, as atitudes, pensamentos e emoções condicionadas pelo Ego possuem uma energia poluída, densa e pesada, ao passo que uma pessoa com energia positiva está vibrando em uma frequência mais elevada e limpa, menos densa.

Seguindo este entendimento, a matéria adquire aí, para os daimistas, outro nome: aparelho, denominação que se justifica na medida em que concebe o corpo físico como um "rádio", ou uma "antena" capaz de sintonizar-se com diferentes frequências e vibrações de energia que podem ser emitidas e captadas "no ar". No momento em que um irmão está em miração, com um aumento considerável de sua sensibilidade, ele pode perceber/sentir tais energias com mais clareza.

Se a matéria/aparelho corresponde ao corpo fisiológico, este é a dimensão física, visivel e palpável de outros corpos mais sutis, imperceptíveis dentro do que se considera um "estado ordinário de consciência". A ideia do corpo limitado às suas condições fisiológicas é deste modo, transcendida, quando se aceita a existência de uma multiplicidade de corpos mais sutis. Estes correspondem à contraparte espiritual, invisível, energética da matéria, que não pode ser tocada nem vista à percepção ordinária, mas apenas sentida.

Nesse sentido, aquilo que se materializa na Terra é antes de tudo energia; em outras palavras, é possível considerar que a matéria, devido ao fato de possuir uma maior densidade que o espírito, é uma manifestação de uma energia primordial, mais sutil. Considerando-se um corpo multidimensional em que ocorre toda uma recursividade entre suas distintas dimensões, a limpeza surge como uma manifestação física, no plano da matéria, de uma energia negativa anterior que um aparelho possa estar sintonizado.

Então é como se o Daime fosse um sugador dessas energias, ele tá dentro da nossa barriga, é como se tivesse um ímã que fica puxando essa energia que está nos nossos outros corpos, aí tem hora que ele puxa tanto que tem que vomitar né, porque ele puxou, ele sugou. Eu acredito que com o tempo a pessoa não vomita mais porque ela já tem tanta firmeza que ela vai trabalhar essa energia. Eu cheguei na doutrina do Santo Daime eu já vinha com muito 
sofrimento da vida, a família muito desregulada [...] e eu tava indo na mesma coisa, histórico de droga, rolos com justiça, e eu sentia muita dor no corpo, mental, sentimental [...] chorava muito no início dos trabalhos. Eu fiquei uns três anos, todo trabalho eu fazia umas limpezas muito 'cabulosas' mesmo, mas fui insistindo e eu lembro que cheguei no limite [...] um dia eu não tava aguentando mais fazer limpeza e fui lá no pé do Cruzeiro e conversei com o Mestre e falei que não aguento fazer limpeza mais não, porque não dá [...] aí foi quando eu comecei a fazer menos limpeza e comecei a firmar mais nos trabalhos, começou a mudar algumas coisas, atitudes externas e tal. Mas sempre tinha uma cura que eu perseguia no Daime, um negócio que eu pedia e fiquei quatro anos rezando, rezava terço todo dia, e essa cura foi começando a acontecer e tá acontecendo ainda. Eu acho que tem gente que acorda mais rápido, passa por esse período de vomitar porque já chega na Doutrina mais limpo, as pessoas que vieram da caminhada do yoga por exemplo né, vão limpar pouco, não vão sofrer tanto né. Eu cheguei na Doutrina muito sujo, imundo na verdade, e eu limpava e ficava limpando, limpando, limpando e eu vejo que a limpeza no Daime, a peia, a passagem inclui muito isso, é uma passagem, então você tá dando uma passagem pra uma coisa que é sua. [...] mas eu digo assim, são tudo cura todas essas passagens, todas elas são cura, mas tem algumas que são mais profundas e elas necessitam de sua matéria pra manifestar, porque é relacionado a seu ser, e o Daime tem um poder de cura que passa por sentir na pele, porque aquele sofrimento que você sentiu na pele você expurga mais rápido o seu pecado entendeu, você paga ele mais rápido, tanto que tem gente que fala que o Daime é um catalisador de carmas, ele transforma carmas muito mais rápido do que várias outras doutrinas né, então às vezes a pessoa limpa no Daime dez vidas dela ali enquanto se ela fosse em outro caminho ia limpar uma de vidas passadas, entendeu? Eu acredito assim a coisa da peia né, eu tô falando da minha experiência, não do que eu li, mas do que eu fui entendendo... (G., entrevista realizada em maio/2016).

O enigma pontuado mais acima, qual seja: "o Daime como um veículo que possibilitaria uma pessoa a encontrar a cura dentro de si mesma" pode, até aqui, ser gradativamente desvendado. Diante do que foi exposto, o Daime é visto, portanto, como um veículo por meio do qual cada irmão pode fazer uma viagem por todo o seu ser, toda a sua consciência e existência. Esta viagem implica em um enfrentamento, em meio às mirações, com o Eu Inferior - o que implica certa dose de sofrimento durante as cerimônias, já que a cura do Daime passa por "sentir na pele", consistindo em verdadeiras batalhas espirituais - na forma de peias, passagens, e limpezas, quando cada irmão tem a oportunidade de receber a "Luz do Daime" para que possa ir iluminando os seus lados "sombrios" e aprofundando o seu trabalho de autoconhecimento.

Desta forma, falar em cura pode ser o mesmo que falar em "autotransformação" e "iluminação espiritual", ou ainda, "salvação" (PELÁEZ, 1994), configurando-se enquanto termos "quase" sinônimos. Inclusive, em muitos dos relatos, os integrantes da irmandade do CLNSS preferiram adotar a ideia de cura enquanto um processo, na busca por uma aproximação cada vez maior, através do autoconhecimento, junto ao Eu Superior - o Ser Verdadeiro, a essência divina existente dentro de cada irmão. A "cura" assume, portanto, uma dimensão mais ampla, de "cura espiritual", que compreende a libertação de um ser do ciclo de reencarnações cuja finalidade é a sua iluminação espiritual.

Se a matéria, porém, pode ser representada como a "casa de um espírito", a cada irmão cabe a disciplina, firmeza e responsabilidade de fazer por merecer que esta casa seja feita um 
lar, ou seja, um ambiente familiar de acolhimento, amor, carinho e respeito - sentimentos e valores que transcendem qualquer limite físico e estrutural de um "frio" local de habitação que constitui a casa. Isso deve acontecer de forma que, metaforicamente falando, não sejam os ratos ou as formigas - ou seja, o Eu Inferior - quem irão dominar a casa, mas sim o Eu Superior, a própria essência divina que habita em cada aparelho.

Nesse sentido, o lar pode ser considerado como um elemento superior que transcende a casa, entendendo-se analogamente a transcendência do Ser Verdadeiro - que não é necessariamente tangível, mas se faz no silêncio, na tranquilidade, na calma, paciência e atenção em tentar sempre, a cada dia do cotidiano, corrigir os seus defeitos - em relação à matéria. O processo de cura pode ser compreendido, assim, como o trabalho constante e permanente em zelar pela manutenção e harmonia do lar, constituindo o alinhamento e comunhão entre o $E u$ Inferior e o Eu Superior, em cada encarnação, até que se atinja certo grau de evolução para não precisar mais encarnar na Terra, quando alcança um patamar de pura iluminação.

Eu acho que é um exercício constante de buscar por essa harmonia, por esse entendimento, por essa cura, uma palavra boa pra ligar com doença é a questão da desarmonia, seja em qual nivel que ela possa estar presente que existiria uma desarmonia, e essa desarmonia vai acarretando efeitos internos, externos, espirituais... é uma eterna luta pra chegar a tão almejada harmonia, eu acredito que eu estou nesse processo, acho que é um desenvolvimento contínuo de uma espiral que cada vez vai crescendo e vão gerando novos entendimentos, vão se curando novas questões. Eu acho que assim, num primeiro momento, eu acho que muita coisa já foi trabalhada, principalmente de relações familiares, de relações interpessoais, que foram negativas, que tiveram algum efeito negativo sobre mim eu acho que essa parte já foi trabalhada, já foi por assim dizer 'curada'. O que eu considero como o processo hoje de cura é o contínuo desenvolvimento interno das suas qualidades, do aprimoramento dos defeitos, de poder estar em contínuo trabalho interno, isso eu considero como uma contínua cura, eu não me considero como curado, algumas questões sim já foram remediadas, mas o processo continua, de comportamentos, pensamentos, traumas... (Ma., entrevista realizada em agosto/2016).

Deste modo, considerando o Eu Inferior e o Eu Superior enquanto dimensões energéticas e invisíveis de um mesmo ser, as atitudes orientadas por cada um desses Eus irão afetá-lo de diferentes formas. Uma energia negativa canalizada recorrentemente por um aparelho, que pode se manifestar em emoções e pensamentos negativos, manifestações do Ego, poderá acarretar grande desarmonia em seus corpos sutis, podendo no limite repercutir em distúrbios a nível físico. Ou seja, considera-se aí que a doença começa nas emoções, passando pelos pensamentos, para só então se manifestar na matéria, como uma desarmonia que se origina nas dimensões corporais mais sutis decorrente de uma sintonia do aparelho com energias negativas - os vícios condicionados pelo Ego - que afetam diretamente o estado de saúde de uma pessoa, sendo que a cura pode se dar através de sua autotransformação que irá agir na raiz da questão. 


\section{CONSIDERAÇõES FINAIS}

A definição de um conceito de "doença" não se reduz, no Santo Daime, às evidências apresentadas por uma diagnose clínica sobre algum ponto localizado do corpo, mas abrange dimensões que em geral não são contempladas pela medicina ocidental. O Santo Daime, enquanto uma "terapia religiosa" integrante de um movimento mais amplo que compreende o boom das "medicinas alternativas" na sociedade ocidental no que se conhece como "circuito da Nova Era", adota uma visão holista de corpo, entendido enquanto um todo integrado que considera as suas ligações com a mente, as emoções, bem como o meio social e espiritual no qual este corpo está inserido (MALUF, 2005; ROSE, 2005; TAVARES, 2012).

A partir da ideia de um corpo multidimensional, nos relatos que foram coletados durante a pesquisa foram encontradas curas em suas mais diferentes manifestações: físicas, psíquicas e/ou emocionais. A "cura espiritual" constitui o pano de fundo por trás dessas outras curas, sendo entendida enquanto um "processo" de cada adepto, podendo ser confundida com sua própria salvação (PELÁEZ, 1994) para a iluminação espiritual. Energia é o elemento comum que faz o elo entre as diferentes dimensões corporais, fazendo delas uma coisa só, e a fé o fator fundamental que permeia as curas entre os daimistas.

Deste modo, a cura do corpo físico, a matéria, irá reagir a estímulos psicológicos, afetivos e espirituais. A saúde é compreendida, então, enquanto um fenômeno integral, interfatorial, multicausal e recursivo de interafetação entre as distintas dimensões de um mesmo ser. Ou seja, o corpo biológico gera uma ideia que vem precedida de um sentimento que vai repercutir com uma vibração de energia por todo o corpo; todas as dimensões estão interrelacionadas em uma conexão e articulação entre espírito-mente-corpo.

Nesse sentido, com esta pesquisa foi possível constatar que a "cura espiritual" se confunde com muitas outras curas, as "curas psicoemocionais" - correspondentes a níveis emocionais e psíquicos, sendo os próprios hábitos, personalidades e comportamentos subjetivos a cada pessoa - e até mesmo "curas físicas". De fato, o processo de cura espiritual encontra-se imbricado com essas outras curas mais objetivas almejadas pela irmandade, que não devem ser consideradas de maneiras dissociadas entre si.

No Santo Daime a aflição adquire significados próprios, e o doente participa ativamente em seu processo de cura. Isso acontece porque um distúrbio físico pode estar estritamente relacionado com uma desarmonia no campo energético que constitui seus corpos sutis, seja por meio de maus pensamentos ou de algum sentimento negativo, manifestados em atitudes destrutivas para com ele mesmo. No caminho de autoconhecimento propiciado pelo Santo 
Daime a cura pode vir, assim, como um aprendizado do doente em novas formas de se portar e de se relacionar socialmente.

Se nos tratamentos biomédicos o doente passa por um processo imediato de despersonalização, se transformando em um objeto, ou seja, um paciente dentro de uma condição extremamente passiva, no Santo Daime o doente é um agente de suas próprias curas, evidenciando-se em primeiro lugar a sua própria autonomia diante de sua recuperação. A objetificação do doente própria à biomedicina (MALUF, 2005; TAVARES, 2012) motiva as pessoas a procurarem outras formas de cuidado, o que em muitos casos é encontrado nas terapias religiosas.

Por fim, é possível inferir que se todas as pessoas possuem uma essência divina, e Deus é perfeição, então todas as pessoas são potencialmente perfeitas. Porém não há que se desprezar também que somos matéria, espíritos encarnados na Terra, ou seja, seres humanos com todas as suas vaidades e imperfeições, que é o que de fato pode vir a gerar as doenças. Seja as doenças físicas, de comportamentos, personalidades, emocionais, traumas, todas elas se encontram em uma interligação e recursividade impossível de se dissociar, assim como os múltiplos corpos que constituem um Ser. Ou seja, no limite a doença é uma ilusão criada pelo apego de cada pessoa ao seu Ego, o Eu Inferior: egoísmos e individualismos de quem não possui uma consciência "ligada" a uma dimensão mais grandiosa que corresponde à Unidade cósmica universal.

\section{REFERÊNCIAS}

ALVES, P. C.; RABELO, M. C. Repensando os estudos sobre representações e práticas em saúde/doença. In: ALVES, P. C.; RABELO, M. C. (Ed.). Antropologia da saúde: Traçando identidades e explorando fronteiras. Rio de Janeiro, 1998. p. 107-121.

ASSIS, G. L. Encanto e desencanto: Um estudo sociológico sobre a inserção do Santo Daime no cenário religioso contemporâneo. Dissertação de Mestrado em Ciências Sociais. Belo Horizonte, FAFICH-UFMG, 2013.

CARDOSO DE OLIVEIRA, R. 0 trabalho do antropólogo: olhar, ouvir, escrever. In: CARDOSO DE OLIVEIRA, R. 0 trabalho do antropólogo. São Paulo: Unesp, Paralelo 15, 2000. p. 17 - 36.

DA MATTA, R. Relativizando. Uma introdução à Antropologia Social. Petrópolis: Vozes, 1981.

GEERTZ, C. "A religião como sistema cultural". In: GEERTZ, C. A interpretação das culturas. Rio de Janeiro: Editora Guanabara, 1989.

KARDEC, Allan. 0 livro dos espíritos. Rio de Janeiro: Federação Espírita Brasileira, 2005 [1857]. 
LANGDON, E. J. A doença como experiência: a construção da doença e seu desafio para a prática médica. Antropologia em primeira mão, $n^{0} .12,1995$.

MACRAE, E. Guiado pela lua: xamanismo e uso ritual da ayahuasca no culto do Santo Daime. São Paulo, Editora Brasiliense, 1992.

MALUF, S. Mitos coletivos, narrativas pessoais: cura ritual, trabalho terapêutico e emergência do sujeito nas culturas da nova era. Mana, v. 11, n. 2, p. 499-528, 2005.

MERCANTE, Marcelo S. Imagens de Cura: Ayahuasca, imaginação, saúde e doença na Barquinha. Rio de Janeiro: Editora Fiocruz, 2012.

MONTERO, Paula. Da doença à desordem: a magia na Umbanda. São Paulo, Graal, 1985.

MOREIRA, Paulo; MACRAE, Edward. Eu venho de longe: Mestre Irineu e seus companheiros. Salvador: Edufba, 2011.

PELÁEZ, Maria Cristina. No mundo se cura tudo: Interpretações sobre a cura espiritual no Santo Daime. Dissertação de Mestrado, Florianópolis, UFSC, 1994.

RABELO, M. A. A construção do sentido nos tratamentos religiosos. RECIIS - R. Eletr. De Com. Inf. Inov. Saúde, v. 4, n. 3, p. 1981-6278, 2010.

ROSE, I. S. Espiritualidade, terapia e cura: um estudo sobre a expressão da experiência no Santo Daime. Dissertação de Mestrado. Florianópolis, UFSC, 2005.

SILVA, V. G. 0 Antropólogo e sua magia: Trabalho de Campo e Texto Etnográfico nas Pesquisas Antropológicas sobre Religiões Afro-brasileiras. $1^{\mathrm{a}}$ ed. - São Paulo: Editora da Universidade de São Paulo, 2015.

TAVARES, F. Alquimistas da cura: a rede terapêutica alternativa em contextos urbanos. Salvador, Edufba, 2012. 